\title{
A Freewheeling Defense of Kant's Resolution of the Third Antinomy
}

Todd D. Janke

Introduction

$\mathrm{I}$ $\mathrm{n}$ the Critique of Pure Reason, in a chapter of the Transcendental Dialectic entitled "The Antinomy of Pure Reason," Kant addresses the question whether a thoroughgoing mechanistic determinism is reconcilable with the ascription of free agency to human beings. In the third antinomy, reason is shown to be divided against itself insofar as both of two competing, and seemingly irreconcilable claims, can be justified on independent grounds; on the one hand, the claim that everything in nature proceeds according to the law of causality - that every event is determined by antecedent events and causal laws; on the other hand, the claim that agents act freely, i.e., that there are some occurrences, namely human actions, which cannot be accounted for by antecedent states or events and causal laws.

Kant's position with respect to the resolution of this antinomy in many ways prefigures some important philosophical developments in contemporary philosophy of action, most notably the position of "anomalous monism" advocated by Donald Davidson, among others, as well as the "intentionalism" advocated by G. H. von Wright and Frederick Stoutland. I think that the latter are particularly helpful for shedding light on of some of Kant's more troublesome remarks, and so in what follows below I will try to put some of their insights to work in clarifying what I take to be ambiguities in Kant's persuasive account of the reconcilability of mechanistic determinism and human freedom. I first give a rough mapping of the terrain by looking closely at the text of the third antinomy and Kant's attempt at a resolution. I then turn to Norman Kemp Smith's criticism of Kant's resolution, responding to that criticism at length with some help from von Wright and Stoutland. My aim in all of this is to show that there is in Kant's resolution of the third antinomy a much more cogent and persuasive philosophical position on agency than is often recognized.

\section{The Third Antinomy}

The thesis in the third antinomy holds that natural causation or what we might call mechanistic determinism in accordance with the laws of physics, is not the only kind of causality operating with respect to appearances in the 
world, and that another kind of causality is required to account for a particular subset of those appearances-in short that freedom is required to account for human actions. The thesis thus stated is fairly straightforward, but unpacking it and the proof offered on its behalf calls for some comment.

The argument for the thesis trades on the notion of causally sufficient determination of events a priori, proceeding, by reductio, to argue that on the supposition that there is no other causality besides mechanistic causality, every event is determined by antecedent events and causal laws. The difficulty here arises when we note that if we continue in pushing the causal chain back, we will never come to a first cause, since the causality of even that cause (if there were one), as something occurring in time-as an event with duration-will itself have to be explained by reference to antecedent events. This infinite open-endedness of the causal chain which appears to be required by a principle of reason enjoining us always to look for the next higher link in the causal chain seems to violate another principle of reason. As Kant writes,

If, therefore everything takes place solely in accordance with the laws of nature, there will always be only a relative and never a first beginning, and consequently no completeness of the series on the causes that arise the one fro the other. But the law of nature is just this, that nothing takes place without a cause sufficiently determined a priori. ${ }^{1}$

The claim that there is no other causality besides mechanistic causality, then, runs itself into a contradiction - it requires both that we explain events by reference to antecedent events and causal laws, and that each instance of causality be sufficiently determined a priori, where "sufficient" determination means something like complete, non-infinitely regressing, determination. ${ }^{2}$ Since this claim about mechanistic causality issues in such a contradiction, we must posit another kind of causality, namely that of freedom-the power to originate a series of events in nature, a power of bringing things about which is not determined by antecedent events and natural causes. Kant describes such freedom as

an absolute spontaneity of the cause, whereby a series of appearances, which proceeds in accordance with laws of

\footnotetext{
${ }^{1}$ Immanuel Kant, Critique of Pure Reason, trans. by Norman Kemp Smith (New York: St. Martin's Press, 1965), 410.

2 The idea that sufficient determination for Kant in this argument means "complete determination" I get from Norman Kemp Smith's Commentary to Kant's Critique of Pure Reason (New York: Humanities Press, 1923), 493. He goes on to remark that Kant's argument here is not valid as it stands, that "each natural cause is sufficient to account for its effect. That is to say, that causation is sufficient at each stage. That the series of antecedent causes cannot be completed is due to its actual infinitude, not to any insufficiency in the causality which it embodies."
} 


\section{KANT'S THIRD ANTINOMY}

nature, begins of itself. This is transcendental freedom without which, even in the ordinary course of nature, the series of appearances on the side of the causes can never be complete. ${ }^{3}$

The antithesis of the third antinomy holds that ascribing freedom as a kind of causality is ultimately untenable on the grounds that free action is precisely something taken to be free from the causal machinations of nature, and it is just those causal machinations which render experience intelligible to us. Without causality holding between events there is nothing but lawlessness among the appearances, and where there is lawlessness there can be no unified experience.

Transcendental freedom thus stands opposed to the law of causality; and the kind of connection which it assumes as holding between the successive states of the active causes renders all unity of experience impossible. It is not to be met with in any experience and is therefore an empty thought-entity. ${ }^{4}$

It is also no good for the proponent of the thesis to argue that lawlessness is not an essential feature of freedom, since in that case the proponent of the antithesis will simply respond by saying that a freedom that is not freedom from lawfulness (causality) is not any kind of freedom at all, but "nature under another name. Nature and transcendental freedom differ as do conformity to law and lawlessness." 5

Finally, the antithesis suggests, the "illusion of freedom" is attractive because it offers some promise of rest from the tireless labor of searching through events after their causes; if we can appeal to freedom of action in explaining the occurrence of some event, we can finally stop looking for further antecedent events. However, the antithesis claims, this kind of causality is "blind," and the only real hope of attaining "completely coherent experience" rides on the back of nature's lawfulness - the coherence of the world in causal terms.

The basis of Kant's response here, and the principle feature of Kant's defense of the reconcilability of freedom and mechanistic determinism, is his appeal to a distinction between appearances (phenomena) and things in themselves (noumena). As noted above, the antinomies of pure reason arise as a result of reason's overextending itself, trying to apply its ideas beyond their properly restricted domain. The claim that mechanistic causality is sufficient for all explanatory purposes represents just such an overextension, inasmuch as it requires what Kant takes to be an ungrounded presupposition-that the

\footnotetext{
${ }^{3}$ Kant, op cit., 411.

${ }^{4}$ Ibid., 410.

${ }^{5}$ Ibid., 411.
} 
appearances exhaust the totality of what there is. "The common but fallacious presupposition of the absolute reality of appearances," he writes, "here manifests its injurious influence, to the confounding of reason. For if appearances are things in themselves, freedom cannot be upheld."6 If we collapse things in themselves into appearances, then we must forfeit freedom, because all appearances must be connected in experience according the law of causality. Since the mind brings this law to experience, and since it is only by virtue of the law of causality that we are able to have experience at all, there can be no experience of freedom; there can be no experience that does not trade on causality for its intelligibility.

But Kant's transcendental idealism gives us a way out of this predicament. In the same way that we must posit a transcendental object behind the appearances given to us in intuition, we must posit an intelligible cause for certain empirical events. ${ }^{7}$ The agent as acting freely, then, can be said to be the causal ground of an action in its intelligible aspect, even thought this intelligible aspect can never be given to us in experience (in a causally connected series of events). For each act there will be both an empirical and an intelligible character, and each will be characterized with respect to the position from which it is viewed. Considered from the perspective of merely empirical phenomena, as a mere appearance given to us in experience, the agent is subject to the causal laws governing appearances in general. From the perspective of its intelligible character, however,

this same subject must be considered to be free from all determination through appearances...And consequently, since natural necessity is to be met with only in the sensible world, this active being must in its actions be independent of, and free from all such necessity...The active being of itself begins its effects in the sensible world. ${ }^{8}$

Once we make this transcendental move, and consider action from different perspectives, we see, says Kant, that the irreconcilability of freedom and determinism is ultimately only apparent, a result of our inability to make a fundamental distinction between appearances and things in themselves. Once we make that distinction, "freedom and nature, in the full sense of these terms, can exist together, without any conflict, in the same actions, according as the actions are referred to their intelligible or to their sensible cause."'

Before turning to my expansion on and defense of these claims, it will be instructive to look at the following remarks by Kemp Smith, since they summarize succinctly the challenge I take up on Kant's behalf below. Kemp Smith argues that the "two view," or appearances/things in themselves

\footnotetext{
${ }^{6}$ Ibid., 466.

7 Ibid., 469.

${ }^{8}$ Ibid.

${ }^{9}$ Ibid.
} 


\section{KANT'S THIRD ANTINOMY}

distinction, ultimately fails to give Kant what he needs to reconcile freedom with mechanistic determinism, for it fails to meet the difficulty of

how, if all natural phenomena constitute a single closed system in which everything is determined by everything else, a moral agent, acting spontaneously, can be free to originate a genuinely new series of natural events. We seem constrained to conclude that Kant has failed to sustain his position. A solution is rendered impossible by the very terms in which he formulates the problem. ${ }^{10}$

Kemp Smith's criticism, in other words, is that Kant's understanding of nature as a closed deterministic system governed by causal laws leaves no room for the moral agent to actually $d o$ anything. For if all events in nature (i.e. all appearances given to us in intuition) are determined by prior events and causal laws, an agent's free choice or decision will have no effect on the course those events take. And insofar as human actions can be considered as empirical events, and thus as appearances, their coming about will exhaustively be accounted for by prior events. In short, then, given that human actions are appearances, they could not possibly be the result of free agency. Let me now turn to a fuller treatment of Kant's response to the third antinomy, by way of defense.

\section{Rescuing Kant's "Two View" Response to the Third Antinomy}

The two different descriptions involved in Kant's "two view" response are different descriptions of, as Kant puts it, the same action. This way of putting the matter, I think, is somewhat misleading, and as a result gives rise to misunderstanding. However, in the passages in the Critique following the text cited immediately above, Kant gives different formulations of this claim which shed some clarifying light on his meaning. At A 543/B 571, for example, he speaks of two views of the same event. Here is how he makes the transition. First he reiterates that the law of causality is a necessary constituent in the unifying of appearances which results in experience. "All events are empirically determined in an order of nature... This law is a law of the understanding from which no departure may be permitted, and from which no appearances may be exempted."11 Next, he argues that even given the necessity of this law, it may be possible that from some vantage point, or to steal a phrase from G.E.M. Anscombe, under some description, action is a result of freedom. Here Kant no longer says that one and the same action can take these different descriptions, or have these different aspects, but rather, he now refers to different descriptions of one and the same event. Thus, he asks whether it is "possible to regard one

\footnotetext{
${ }^{10}$ Kemp Smith, op cit., 518.

${ }^{11}$ Kant, op cit., 470.
} 
and the same event as being in one aspect merely an effect of nature and in another aspect an effect due to freedom?"12 And he goes on in an important text to conclude that

Among the causes in the [field of] appearances there certainly cannot be anything which could begin a series absolutely and of itself. Every action [viewed] as appearance, in so far as it gives rise to an event, is itself an event or happening, and presupposes another state wherein its cause is to be found. ${ }^{13}$

Notice that Kant does not say here that actions are events simpliciter, but only secundum quid, i.e., only insofar as they give rise themselves to events. Under the description "event which gives rise to other events" an explanation of an action in its empirical aspect may (perhaps must, to be a genuine explanation in this sense) look for its originating sources in antecedent events and causal laws. But this will only be an explanation of one aspect of an action, and not, in particular, an explanation of it as an action. Action explanation, it seems, is not (really) a causal affair at after all: "An original act, such as can by itself bring about what did not exist before, is not to be looked for in the causally connected appearances."14

This passage raises a bit of a difficulty, specifically with respect to the question of what it might mean in this context for an action by itself to bring about what did not exist before, and how this "bringing about" which actions accomplish can be cashed out in non-causal terms. To say that an action can bring about what did not exist before, and that the explanation of this is not something we could discover by looking at the causal connections between appearances, should draw our attention to the important ways in which action descriptions individuate differently than physical descriptions, where "physical descriptions" refers to whatever we can describe as covered by causal lawseverything in experience subject to the laws of physics. Let me try to spell out those differences.

We may say that an action brings about something that did not exist before-brings about movements of limbs in various way, for example-and note that the point Kant is making about freedom in this regard is just that no individuation in merely physical terms, no physical descriptions of the movements of bodies in various ways, will give us a description of an action. In fact, things seem to be just the opposite-it seems that only in terms of the action description are we able to give a corresponding physical description. What it suggests, in other words, is that it is the action description (a description which includes essential reference to an intelligible character) which is central in marking out what the "it" is that gets brought about. Here the

$$
\begin{aligned}
& { }^{12} \text { Ibid. } \\
& { }^{13} \text { Ibid. } \\
& { }^{14} \text { Ibid. }
\end{aligned}
$$




\section{KANT'S THIRD ANTINOMY}

action description plays the crucial and ineliminable role of picking out from the myriad bodily happenings-from the miscellany of descriptions that a purely physical description in bodily motion terms would yield-some set of them as the item to be explained. 15 The physical descriptions, that is to say, do not gather themselves together in any particular way, and to pick out some item as the one to be described and explained (physically or intentionally, empirically or intelligibly) requires an appeal to actions. ${ }^{16}$ So, what we ought to take Kant to be saying here is that, though actions do take physical descriptions which can be accounted for in terms of causality, nevertheless, it is only on the basis of our taking agents as acting, only on the basis of descriptions of their behavior as action, that the motions of limbs (mere behavior) show up at all as items to be explained.

\section{The Causal and Conceptual Elements in Action}

Acting, properly speaking, then, does not cause events (only events can cause other events), though actions have descriptions, namely physical ones, which figure in the causal explanation of events. To spell out the role of action in the causal story we may say a couple of things. First, acting is a part of a causal story in that acting brings it about that certain antecedent events can be individuated as the events they are, i.e., they can be individuated as the causal antecedents of the bodily motions that take some physical description in light of the action description. Given the action and its descriptions, those events become, in a sense, causal antecedents to the action. If I open a door, for example, I bring it about that certain states of my body, including brain states and events, were the causal antecedents of the behavior involved in that act. ${ }^{17}$ Because they can be described physically, then, actions are connected causally to antecedent states and events which the actions, by virtue of the descriptions as actions, in some sense, bring about (i.e. bring about as individuated in terms of their causally antecedent role with respect to the actions in question).

Second, acting may also be said to originate a new causal sequence insofar as the results of our actions, the descriptions of which results are intrinsic to our descriptions of the actions as the actions they are, themselves can be given physical descriptions as events. In that case acting can also be said to bring about events that can be explained causally as the consequences

15 For these formulations, see Frederick Stoutland, "Davidson on Intentional Behavior," in Actions and Event, ed. by Ernest Lepore and Biran McLaughlin (Oxford: Basil Blackwell Publishers, 1985), 54-59.

${ }^{16} \mathrm{G}$. H. von Wright puts it like this: "What constitutes the unity of the outer aspect of an action is not, be it observed, the causal tie linking its various phases. The unity is constituted by the subsumption of the phases under the same intention." Explanation and Understanding (Ithaca: Cornell University Press, 1971), 89.

17 I take this notion from G. H. von Wright. He writes that the "result of a basic action may have necessary, and also sufficient, conditions in antecedent neural events (processes) regulating muscular activity. The neural events I cannot 'do' by simply making them happen. But I can nevertheless bring them about, vi\%. by performing the basic action in question." Ibid., 77. 
of the results of our actions. This way of putting the matter I get from von Wright, who writes,

When we say that the cause brings about the effect, we do not mean that the cause by doing something brings this about. Thanks to the fact that it happens, the cause achieves this. (The verbs "achieve," "bring about," "produce," are all loaded with metaphors from the language of action.) But by making the cause happen, we achieve or bring about the same as the cause does by happening. To say that we cause effects is not to say that agents are causes. It means that we do things which then as causes produce effects, "act" or "operate" as causes. ${ }^{18}$

If Kant is going to maintain that freedom is a kind of intelligible causality, I think that we must interpret him along these lines. In this light, then, there is a sense in which action is a causal affair, and a sense in which it is not. In the first case, action is a causal affair because the results of our actions have consequences that we can account for in terms of causality. In the second case, action is not a causal (empirical) affair, but a conceptual one, in the sense that the tie between actions and their results is not an extrinsic, nomic tie, but an intrinsic, conceptual tie. Here is von Wright: "If the result [of the action] does not materialize, the action simply has not been performed. The result is an essential 'part' of the action. It is a bad mistake to think of the act(ion) itself as the cause of its result." 19 That Kant takes action to be a conceptual matter, in the sense under discussion here, and not a causal (empirical) one, is strongly suggested by remarks like the following. The text is important, so I will quote it at length.

'Ought' expresses a kind of necessity and of connection with grounds which is found nowhere else in the whole of nature... When we have the course of nature alone in view, 'ought' has no meaning whatsoever...This 'ought' expresses a possible action the ground of which cannot be anything but a mere concept; whereas in the case of a merely natural action the ground must always be an appearance. The action to which the 'ought' applies must indeed be possible under natural conditions. These conditions, however, do not play any part in determining the will itself, but only in determining the effect and its consequences in the [field of] appearance. ${ }^{20}$

\footnotetext{
18 Ibid.,69.

${ }^{19}$ Ibid., 68.

${ }^{20}$ Kant, op cit., 473.
} 


\section{KANT'S THIRD ANTINOMY}

And, he continues,

Reason does not here follow the order of things as they present themselves in appearance, but frames for itself with perfect spontaneity an order of its own according to ideas, to which it adapts the empirical conditions, and according to which it declares actions to be necessary, even although they have never taken place, and perhaps never will take place. ${ }^{21}$

Let me briefly mark another illuminating parallel here between Kant's and von Wright's anti-causalism about human action. Von Wright has consistently rejected a causal account of action, and in that spirit has persisted in denying the legitimacy of the demand on a theory of action that it explain why mere behavior or mere bodily happenings occur on the occasions when an agent acts, for it seems that just putting the question this way already begs it in favor of causalism. Von Wright's claim, then, that the demand for an account of the occurrence of behavior is illegitimate, is remarkably similar to Kant's. Compare the following texts, the first one from von Wright.

It is of the very essence of an action, such as for example the opening of a door, that behavior should occur, e.g. the seizing of a handle and the pulling. Acting without behaving would be magic. Action entails behavior and therefore also 'mere' behavior...It is a basic fact about man, about his 'natural history,' that he can act, do various things...Perhaps we should call the fact that men can perform actions a 'mystery'-in the sense that it is something basic which defies explanation...We can wonder at this mystery - as we may wonder at the fact that man can know things or that there is an external world. It is interesting to note that wonder of this type can be both the starting point and the end station of philosophical inquiry. ${ }^{22}$

Here is Kant:

But to explain why in the given circumstances the intelligible character should give just these appearances and this empirical character transcends all the powers of our reason, indeed all its rights of questioning, just as if we were to ask why the transcendental object of our outer

${ }^{21}$ Ibid.

${ }^{22}$ G. H. von Wright, The Philosophy of Georg Henrik, von Wright, ed. by Hahn and Schilpp (La Salle: Open Court, 1989), 809. 


\section{T. JANKE 119}

sensible intuition gives intuition in space only and not some other mode of intuition. ${ }^{23}$

The upshot of these remarks may be put by saying that questions about action are conceptual questions, while questions about the occurrence of events are empirical questions, and that each has its own explanatory bailiwick. ${ }^{24}$ Actions differ from events, we could say, because descriptions and explanations of the former are part of what Wilfrid Sellars has called "the space of reasons"- they are actions insofar as they are part of those social exchanges which involve giving and asking for reasons (in the sense of rationale, or justification). The trouble, of course, with putting things this way is that some will claim that the "intelligible" aspect of action description is in each case reducible to it "empirical" aspect-in short, that action descriptions are eliminable, and that we can get by with descriptions of actions in purely physical terms. I think this rejoinder is ungrounded, but that it nevertheless motivates much of the resistance to Kant's view. Responding to it should help us see where critics, like Kemp Smith, go wrong.

The main mistake made by those who think that Kant's attempted resolution of the third antinomy ultimately fails because a reduction of action to events (mere behavior, or bodily happenings) is in the offing, comes by way of taking Kant to be arguing for a resolution in terms of two views of the same action. This is to overlook the fact that it is only owing to the intelligible character of the agent we ascribe an action to her at all, and not simply mere bodily movements. When Kant speaks of the same action looked at from different aspects he cannot be taken as meaning this in any ontologically robust sense. That is, he cannot literally mean "the same thing," and particularly he cannot mean "the same action." Talk of action, on Kant's view, should be restricted solely to talk at the intelligible level. An explanation of the physical aspects of action in light of causality is not an explanation of action.

It would be better, then, though there is still risk of misunderstanding, to say that what we have in Kant's suggested solution are two views of, or two different ways of characterizing, behavior, and leave the sense "behavior" open. For then we can qualify behavior subject to and explicable in terms of mechanistic causal laws mere behavior, and behavior subject to free agency intentional behavior. This way of putting the matter has the distinct advantage that it does not simply beg the question of which is more basic for explanation, mere behavior or intentional behavior, since it is ambiguous on whether mere behavior is intentional behavior stripped of its intentionality, or whether intentional behavior is mere behavior invested with intentionality. ${ }^{25}$ Given

23 Kant, op cit., 478.

24 This is another way of saying that actions fall under the rubric of normative assessment, while events, strictly speaking, do not. Kant thought of concepts as rules, in a certain sense, so I think putting the matter this way is not far from his meaning. (Of course, the distinction between the conceptual, or normative, and the empirical, is itself a normative distinction.)

25 For this formulation I am indebted to von Wright. 


\section{KANT'S THIRD ANTINOMY}

Kant's general commitments, and the texts cited throughout, it seems more appropriate to saddle him with the former view. This also squares better with everyday experience, and the phenomenological evidence, since for the most part we just see people as acting, as doing things intentionally, before we form notions of their behavior as mere bodily happenings. ${ }^{26}$ It's rare (indeed it would seem to be a mistake) to ask for a (reasons) explanation of something we take to be a collection of mere bodily happenings and then subsequently come to discover that it's intentional behavior. It's more common, by contrast, to ask for an explanation for what we take to be intentional behavior, and then come to discover that there was no reason for it, that it wasn't intentional behavior after all.

\section{Conclusion}

By arguing as I have here, I've put myself squarely at odds with some of Henry Allison's remarks about Kant's resolution of the third antinomy. I close here by showing where I think Allison goes astray. Allison writes of the empirical character of agents in Kant that

construed dispositionally, this character can be inferred from 'appearances,' that is, from behavior. The basic idea here is that a person's behavior exhibits sufficient regularity so as to enable one to reconstruct the rule or principle on which that person tends to act in given situations. ${ }^{27}$

In light of what I've said above, the problem is that to read off a rule or principle of action from an agent's behavior we must already be able to pick out features of that behavior that we take to constitute it as intentional behavior. Not just any bodily movements will do, for only intentional behaviors manifest action from a maxim. If we consider the myriad ways in which any particular action from a maxim can be instantiated (the countless physical descriptions we could give of an act of charity, for example), we then realize that unless we are already able to grasp the connection between dispositional characters and behavior in seeing behavior straight off as action we wouldn't be able to see them all as instances of a certain kind of action from a maxim - we'd have no way to generalize about how people with certain dispositions act. This is all just to say that the ascription of a disposition to act from a maxim must already be included in our description of the behavior as intentional, and thus the connection between behavior and dispositions in

\footnotetext{
26 Fred Stoutland's work has helped me to see the importance of this kind of phenomenological evidence in philosophy of action.

${ }^{27}$ Henry Allison, Kant's Theory of Freedom (Cambridge: Cambridge University Press, 1990), 33.
} 
most cases is not made by drawing inferences between them. ${ }^{28}$ Consider the difficulty in marking the parameters of the behavior on the basis of whose sufficient regularity on is supposed, on Allison's reading of Kant, to be able to reconstruct a rule or principle of action. The ambiguity built into "behavior" and "behavior which exhibits sufficient regularity" is staggering-it in no way distinguishes behavior as something that merely happens (Aquinas's actus bominis), from behavior in the sense of something that we do (Aquinas's actus bumanae). Since behavior in both these senses can be said to exhibit sufficient regularity, it cannot be on the basis of observations of mere behavior that we are able to generalize about the ways in which people with various dispositions act-no matter how much regularity we observe in my sweating, digesting, or breathing behavior, we will never be able to extract a maxim or rule of action from it.

What Allison ascribes to Kant cannot be what Kant had in mind. When we grasp the intelligible character of actions by learning to see behavior straight off as action, this cannot be the result of drawing inferences from behavior-that the behavior has this intelligible character belongs to our very perception and description of the action. This intelligible character, I think, is something that we must attribute to agents to be able to make sense of them at all. In that sense, then, the appeal to the intelligible, to the free causality of agency, is ineliminable. We simply cannot get by without it. Seeing that, as Kant did, shows us how mechanism in nature can ultimately be reconciled with free agency.

\section{Department of Communicative Arts \& Integrative Studies, Clayton State University, United States}

\section{References}

Allison, Henry, Kant's Theory of Freedom (Cambridge: Cambridge University Press, 1990).

Kant, Immanuel, Critique of Pure Reason, trans. by Norman Kemp Smith (New York: St. Martin's Press, 1965).

Smith, Norman Kemp, Commentary to Kant's Critique of Pure Reason (New York: Humanities Press, 1923).

Stoutland, Frederick, "Davidson on Intentional Behavior," in Actions and Event, ed. by Ernest Lepore and Biran McLaughlin (Oxford: Basil Blackwell Publishers, 1985).

, "Reasons, Causes, and Intentional Explanation," in Analyse \& Kritik, 8 (1986), 28-55.

von Wright, Georg Henrik, Explanation and Understanding (Ithaca: Cornell University Press,1971).

${ }^{28}$ Cf. Frederick Stoutland, "Reasons, Causes, and Intentional Explanation," in Analyse \& Kritik, 8 (1986), 28-55. 
122 KANT'S THIRD ANTINOMY

, The Philosophy of Georg Henrik von Wright, ed. by Hahn and

Schilpp (LaSalle: Open Court, 1989).

